\title{
THE MANAGEMENT OF MASS SURGICAL CASUALTIES IN NUCLEAR WAR
}

\author{
Major-General R. A. STEPHEN, \\ C.B., C.B.E., Q.H.S., M.D., Ch.M., F.R.C.S., late R.A.M.C. \\ Director of Army Surgery and Consulting Surgeon
}

\section{Introduction}

THE management of mass casualties in global war is a vast subject. Modern surgery with its ancillary aids which has so much to offer to conventional battle casualties is necessarily restricted when numbers complicate the scene. While it is difficult to picture the horrors of mass destruction it is, unfortunately, no new subject. On the banks of the upper reaches of the river Nile, near the valley of the Kings, the ancient Egyptian kings recorded on stone their overwhelming victories by depicting battle scenes on the walls of their tombs. Hundreds of corpses were piled on top of each other over the extensive battle fields. No doubt vultures, rats and crocodiles did a lot of scavenging. On one tomb the stonework shows that the military surgeons of the day seemed to have been busy with hatchets and cauteries. The captive bowmen had had the left hand amputated to prevent further archery, without making them useless as slaves. The methods of clearing future battlefields should be somewhat different.

In 1958 the NATO nations agreed on the basic methods of emergency surgical treatment to be provided in conventional war for the wounded who might be cared for by medical services, other than their own. The purpose of this surgical standardization was to ensure that definitive treatment, as distinct from emergency treatment, could be provided by the national surgeons at home, just as if these surgeons had provided the entire treatment from the time of wounding. The wisdom and foresight of that agreement was seen recently in the Far East, where casualties benefitted from that very standardization.

The basic methods were described in the first NATO Emergency War Surgery Handbook, published under the auspices of SHAPE, and included by the United Kingdom in the Field Surgical Pocketbook (1962). In 1965 a new section dealing with the management of mass surgical casualties was added to clarify what action should be taken to salvage survivors.

In the event of sudden unexpected disaster with mass casualties, survivors will be hard put to it to know what to do. Few will have had actual previous experience to guide them. At the end of the 1939-45 war the horrors of cleaning up the Sandbostel concentration camp in Germany made a profound impression on all who took part. One common grave mound was said to contain 49,000 Russian bodies. These had become corpses over a four month period of starvation. Among the survivors were a few scarecrows scantily clad in rags who behaved almost like wild beasts. They trampled on anyone to gain whatever food they could lay their hands on. Others were apathetic, spiritless and waiting for death, while a few lay naked in the mire, using corpses for pillows.

To balance that terrible picture it is worthwhile recording the behaviour of a badly burned British tank driver. During the fighting in the Western Desert just outside 
Tobruk, earlier in the war, an anti-tank shell put his tank out of action and set the petrol on fire. His left foot was immovably trapped by the in-driven side of the tank and his left leg was fractured just above the ankle. His companions could not get him out of the blazing tank. In desperation he cut off his own foot through the fracture line with his jack knife and escaped through the turret of the tank leaving his foot behind him. When his wounds were treated in the casualty clearing station he was calm and unperturbed. His stoical bearing deceived everyone. There was no indication of what had happened until his story was extracted from him with difficulty. The odd appearance of his amputation stump was unusual and had aroused the surgeon's curiosity. This brought the story to light.

When overcome with depression at the ghastly picture of desolation conjured up by thoughts of the destruction and suffering of total war, this soldier's courage, determination and fortitude kindle a spark of hope.

\section{Management in Conventional War}

The problem of the management of mass surgical casualties requires realistic study to make full use of the resources remaining. It is easier to plan successfully in nuclear war if the organization for conventional war is first considered and analysed. This depends essentially on the three following phases which are fully described in the Field Surgical Pocketbook 1962.

The first phase consists of skilled first aid and primary evacuation towards the emergency surgery of wound toilet.

The second phase which follows consists of adequate pre-operative resuscitation followed by skilled anaesthesia and meticulous wound excision, within six hours of wounding. Skilled post-operative nursing care is provided so long as this is required.

The third phase consists of further evacuation to a major base hospital, for delayed primary suture and definitive surgery.

Unfortunately at the beginning of every military operation the lessons of the past have always been forgotten because in peacetime conditions all these factors are automatically provided and taken for granted, with the exception of phase three. All surgeons dealing with patients who have been injured in civilian traffic accidents have their own orthodox ways and means of treating them. These methods often include immediate intra-medullary nailing of fractures. The surgeons know from their past experience what is likely to happen. They can anticipate complications. In these circumstances the majority of patients recover successfully from their injuries having been kept under close superyision by the same team of medical attendants. It seems it would be folly to ignore such well established measures.

Phase three is the unknown factor of which the civilian peacetime surgeon has little or no experience. It upsets post-operative management completely. Forward units must be kept empty to deal with fresh casualties. Further evacuation post-operatively becomes essential. The anaesthetist must play a major role in deciding the fitness of the patient for this evacuation. Standardization of management and team work must be practised throughout the Army. Brief legible notes are the links between team members who are miles apart. The surgical necessity for delay in primary suture and further delay in definitive treatment of fractures is not obvious to civilian surgeons and seems a heinous crime, Sepsis following the post-operative evacuation of patients whose wounds were 
closed by primary suture, has in past campaigns converted all civilian surgeons in uniform. Sepsis has won the battle in spite of the advantages of antibiotics, when these disciplines have not been practised. Even as recently as the earthquake disaster at Skopje in Yugoslavia, some wounds were closed by primary suture, with the inevitable onset of major gas gangrene.

\section{Mànagement in a Disaster}

When the surgical potential of an area is, or is about to be, overwhelmed beyond its capacity and with no hope of immediate outside assistance, even the standards of conventional war will no longer be possible. At the outset of such a mass casualty situation it is imperative that the senior administrative medical officer, in immediate charge of the area, proclaims a "State of Emergency", during which a completely different conception of surgical management will apply. If chaos is to be avoided the order that the medical services have "changed gear" must be precise and made known to all concerned. When the surgical situation improves the standards will be improved as circumstances permit. It is of the utmost importance that everyone appreciates the significance of the change in the tempo of surgical treatment, because this is the foundation on which the planning organization must build.

The surgical problem must be studied from the practical point of view omitting all vague and ill defined terms. An expression such as "life-saving surgery" is vague and misleading if the patient dies next day. The phrase "the greatest good for the greatest number" means nothing concrete and should likewise be avoided. Unless planning is realistic it will achieve little and will waste effort in the wrong direction. Facts must be faced, no matter how unpleasant they may be. In view of the difficulties to be overcome in such devastation, and realising that casualties will be treated with what is actually available, in the time available, the key question will be - "who in seven days time is likely to be alive, with a fair chance of eventual recovery?" Selection might even go further and give priority in treatment to those who will be fit to fight within seven days.

\section{Unexpected Survival}

It should never be forgotten however, that throughout the ages the human body has survived unaided, by means of its natural defence mechanism, in spite of a vast variety of injuries. Many apparently moribund casualties have survived in spite of everything. Diagnosis for instance may have been wrong. This was so when a sentry on duty appeared to have blown his face off accidentally. He had fallen asleep while resting his chin on the end of the barrel of his loaded rifle. At first sight his whole face seemed to have disappeared with froth bubbling out of a hole in his neck as he breathed. He looked beyond all human aid and could well have been set aside, yet after adequate resuscitation and meticulous surgery he made a miraculous recovery. The bullet had passed from the entry wound just above his larynx to the tip of his nose having split his tongue to its root in the midline and having shattered the front of his mandible and premaxilla. Eleven months later he had practically no disability.

For nuclear disaster and mass casualty situations the Priority Categories for surgery have been radically revised. This has been necessary to avoid waste of effort on account of the devastation, the vast number of injured, the passage of time, and the distances involved in transportation. 
High velocity missile wounds with their extensive disruption of tissue should not be a problem in these circumstances. The main concern will be with the less seriously wounded who are most likely to survive. It will be necessary to assess quickly the chances of recovery of patients suffering from multiple injuries. These may include moderate burns, contusions, open wounds of varying extent and degree, fractures and limited crush injuries. Degrees of severity will vary from trivial flash burns with temporary blindness to immediately fatal conditions.

When management and treatment are considered, it will be essential to assess the effects of complications such as anoxia, shock and infection, in relation to the passage of time and the effects of transportation. The clinical picture will change from hour to hour. For example 6 hours after injury the surgical picture will be quite different from that found 24 hours later. It will be different again at the end of 48 hours. The evacuation position will likewise change. The planning must therefore be flexible and related to the nature of treatment, whatever the conditions.

Surgical treatment should be considered under the following three headings:Firstly-first aid measures.

Secondly-urgent emergency surgery.

Thirdly-delayed surgery.

Phase one-Many people fail to appreciate that Self-Aid is all that may be available. Simple non-operative measures of first aid will include the following:-

(a) Establishing a clear air-way by turning the casualty into the coma position. Equally important, if there is a sucking wound of the chest the need will be to make the hole airtight. The casualty himself may be able to do this.

(b) The prevention of blood loss on wounding is of the greatest importance. It may be achieved by digital pressure over the affected blood vessel against bone. If this is done immediately on wounding it not only saves blood but in turn saves blood transfusion and the risk of virus hepatitis or incompatability due to the errors of harassed laboratory technicians. The blood is already in circulation and is independant of logistics. No tourniquets endanger limbs.

(c) Wound infection may be prevented and return to duty will be expedited by the skilled application of a sterile dressing, so that it stays in place without exposing the wound. This saves antibiotics. No syringes will be required.

(d) Early immobilization of a fracture by first aid measures may save an amputation. The standard emergency Plaster of Paris pack and methods of application of plaster slabs should be known to all. With a limb safely splinted pain will be lessened and the patient may be able to crawl.

(e) The patient immobilized by more serious injury can save his own skin and avoid pressure sores by the repeated easing of his pressure points and by constantly exercising the uninjured parts of his body if he has been trained in first aid. This will stand him in good stead if antibiotics run out before his turn arrives.

(f) Patients suffering from moderate burn wounds will have a much greater chance of survival if they have an adequate supply of salty oral fluids within six hours.

Phase two-Urgent Emergency Surgical Procedures should include the surgical control of accessible haemorrhage, the amputation of shattered limbs and the provision of dependent drainage for the relief of pus under tension. Since there will be nothing 
better to offer; these procedures must of necessity be brief and life-saving, with a potentially good prognosis post-operatively, irrespective of the time factor since the injury was inflicted. These procedures must be weighed against the certainty of death if left untreated, whether the wound is as early as 6 hours or later than 48 hours from the time of wounding. The operative procedures must also be related to an evacuation journey, whether it be a short journey or a long one. Other additional adverse factors will influence the selection of patients. It is important to consider the effect of minimal pre-operative resuscitation, limited anaesthesia and minimal post-operative nursing. The adverse complications of unrelieved anoxia, oligaemic shock and infection will colour the picture.

Phase three-Delayed Surgery of Survivors is quite a distinct field of surgery with very difficult problems of its own. Due to chaotic conditions it will be a practical measure only after seven days. It will probably take place at a distance from the incident. The general condition of the patient should be sufficiently stable to enable him to survive evacuation. Surviving surgeons will be fully employed attending to the urgent aftermath of wound infection. There will be an overwhelming and immediate need for wound closure. The definitive treatment of fractures, and other injuries, along with procedures such as the grafting of burns will have to wait a more opportune time.

\section{Major Wounds}

Against that background of surgical management, major wounds of the trunk and their complications must be considered as a single group, for which surgery cannot be made available in the first instance, because of time and numbers. They must be treated expectantly by non-operative measures. Many patients with abdominal wounds will die from complications such as haemorrhage, peritonitis, prolapse of wound contents, intestinal obstruction, fistulae or gas gangrene. Some however will survive. Likewise patients with chest wounds and blast injuries may die from haemorrhage, infection or respiratory derangement. Patients with intracranial and spinal injuries will be in various depths of coma or degrees of paralysis for which little can be done. In contrast to trunk wounds, major limb wounds will be much more amenable to first aid measures, but unfortunately patients with lower limb fractures may not escape the flames.

Burn casualties will certainly be a significant problem since adequate treatment will not be possible. Those with 15 to 25 per cent burns will be more likely to profit from available fluids if these are given as early as possible. Once their fluid balance has been stabilised their chances of survival will be greatly improved.

That roughly will be the problem. Operative surgery has very little to offer when faced with overwhelming numbers. More lasting good will come from effective first aid and non-operative measures, such as the dressing of wounds and the application of splints. Surgical procedures must be limited to twenty minutes per patient on average to cope with the problems and on account of the numbers involved. This is well illustrated by a very unfortunate incident in a casualty clearing station near Thebes in Greece during April 1941, when a very competent surgeon spent three hours struggling to deal with a grave intrathoracic wound. The casualty clearing station was filled to capacity with battle casualties. His patient died next day. During the three precious hours, three patients with tourniquets in position awaited amputation of mangled limbs. They had no other injuries. Twenty minutes is given as a guide to what may be possible, and not as an excuse for bad hurried surgery. 


\section{Selection for Surgery}

Following the review of the injuries to be expected and the practical surgical answers available, the method of selection and categorisation of surgical casualties requires clarification. In particular the categories must be clear cut, accepted by all and adhered to. The selection is based essentially on common sense and on the lack of generous resuscitation measures. It must be initiated as near the scene of disaster as is practicable, to avoid the deleterious affects of travel and evacuation, on the seriously injured with blood loss.

The trauma inflicted by the physical effects of the evacuation alone may kill the patient: the irregular movement of a patient lying on a stretcher overcoming his natural defences which have been trying to maintain his circulation. This was very obvious to the surgeons who took part in the opening phases of the Wavell campaign during December 1940 in the Western Desert of Egypt. The first leg of the evacuation journey towards surgery was over eighty miles, across featureless desert. Only two patients with abdominal wounds reached the casualty clearing station. They had both stopped bleeding internally. The fact that a casualty has survived 24 hours, before rescue, does not mean that he can survive a long evacuation journey. The difficulties in 1940 were even greater than usual; transfusion fluids were extremely scarce; many patients missed the staging posts in that featureless wilderness. The unsatisfactory setting of Plaster of Paris slabs caused grave suffering. That in turn led to the problem of over dosage with morphia. Combatant soldiers used their own syrettes of morphia for their wounded companions, without making any record of having given an injection.

In nuclear war when the medical services will be overwhelmed, the system of selection and categorisation for treatment and evacuation must be simple, comprehensive, flexible and efficient. Additional trauma from irradiation, chemical and biological warfare, must also be considered to ensure that there is no waste of surgical effort.

\section{The Alphabet of Surgical Management in Nuclear War}

To avoid confusion with conventional war, letters are used instead of figures in the classification of casualties. This can conveniently be regarded as the $A B C$ of Surgical Management. To meet the requirement five categories are needed-A, B, C, D and E.

$A$-this category stands for Active Surgical treatment. It caters for those patients requiring immediate evacuation for immediate active treatment, by the nearest surgical team. It will include only those who will be fit to stand emergency surgery of short duration, with a good chance of post-operative survival. Such cases may require control of accessible major haemorrhage, amputation or decompression and dependent drainage of wounds. Burn casualties of from 15 to 25 per cent requiring fluid replacement may be placed in this category.

$B$-this category stands for Brief evacuation of the Badly injured. Minimal movement is the key to this category. Casualties should be held in the nearest holding unit. Many of them when dressed and adequately splinted will be fit to be transferred to Category D for further evacuation. They should be given sustaining treatment and emergency care, providing for the relief of pain and the dressing of wounds.

$C$-this category is for the Curable Casualties and the more lightly injured. The patients will be mostly walking and sitting cases. Many will have upper limb injuries. Only minimal treatment will be provided. The policy should be that they will be treated 
once and once only until such times as the situation is under control medically. A few may be detained in a medical centre while others will be sent to non-medical centres.

$D$-this category stands for Distant evacuation. It should include all those who will be fit for distant evacuation without further immediate treatment.

$E$-this stands for Expectant treatment. Many patients will have trunk injuries or extensive burns. They may be held at the nearest medical unit or on the other hand they may be sent to wherever they have the best chance of attention.

\section{Conclusion}

Everyone should learn how to play any role in the scheme of things. First aid assessment is a skilled art based on clinical knowledge, observation, minimal examinnation and common sense. Time, surgical shock, wound infection and the effect of evacuation are the dictators. Chaos can be converted into purposeful order, effort eliminated and survival encouraged by adopting the classification described. Success and survival will depend on a favourable compromise.

\section{Royal Society of Medicine}

Major-General R. A. Stephen, Director of Army Surgery, has been elected to the Council of the Section of Surgery at the Royal Society of Medicine as a Vice President.

\section{OBITUARY}

Brigadier Sidney Smith, M.B., F.R.C.P. died suddenly at Epsom on 19th October, 1966. After the First World War, during which he was for a time a prisoner of war, tours of duty followed in India and Hong Kong. Contemporary and junior colleagues have paid tribute to the memory of the man and his work in Middle East in the Second World War.

Brit. med. J. 2, 1078.

Major-General D. M. Ahern, C.B.E., D.S.O., died suddenly in the Royal Herbert Hospital, Woolwich on 31st October, 1966. He had only recently taken over from his brother Major-General T. M. R. Ahern as D.D.M.S., Eastern Command following tenure as D.D.M.S., H.Q., 1 Corps and Inspector of Training at Ministry of Defence. D.S.O. in 1944, C.B.E. in 1962, service on the Indian Frontier, in Iraq, Burma and North West Europe.

Educated at Ampleforth and Trinity College, Dublin his service took him from the North West Frontier of India to 21 Army Group and Berlin. His knowledge of the Corps was deep, personal and devoted. A Memorial Mass of requiem was said in the Memorial Chapel of the Queen Alexandra Military Hospital on Tuesday 22nd November, 1966 before a large congregation.

Our sympathy is extended to Mrs. Ahern and her family and to Major-General T. M. R. Ahern.

Brit, med.J. 2, 1206. 